\title{
The first kidney transplantation after recipient and living donor recovered from COVID-19
}

\author{
D Eyup Veli Kucuk, ${ }^{1}$ (i) Dede Sit, ${ }^{2}$ (i) Hasan Kayabasi, ${ }^{2}$ (i) Ahmet Tahra, ${ }^{3}$ (i) Resul Sobay, ${ }^{1}$ \\ Seyma Nur Gunes Yilmaz, ${ }^{4}$ iD Cagla Karaoglu, ${ }^{4}$ (D) Ezgi Ersoy Yesil² \\ ${ }^{1}$ Department of Urology, University of Health Sciences, Umraniye Training and Research Hospital, Istanbul, Turkey \\ 2Department of Nephrology, University of Health Sciences, Umraniye Training and Research Hospital, Istanbul, Turkey \\ ${ }^{3}$ Department of Urology, Istanbul Medeniyet University Faculty of Medicine, Istanbul, Turkey \\ ${ }^{4}$ Department of Internal Medicine, University of Health Sciences, Umraniye Training and Research Hospital, Istanbul, Turkey
}

\begin{abstract}
SARS-CoV-2 is still a major threat to the world. In this pandemic, transplantation activities have largely been affected worldwide. We are still facing with this pandemic; however, after regulations, we have started our transplantation activities. We report the first kidney transplantation whose recipient and living donor recovered from COVID-19. A 31-year-old male with renal failure was admitted for transplantation with an ABO-compatible relative. The recipient and the donor were tested for COVID-19 before transplantation, and they were both positive with a polymerase chain reaction. The recipient had minor symptoms and received therapy; the living donor also received therapy. Thirty days after recovery, surgery was performed successfully. The recipient was discharged with mycophenolate mofetil (MMF), tacrolimus, and steroid 15 days after surgery. In the follow-up, they were both negative for COVID-19 45 days after surgery. Although there is missing literature regarding safety concerns and short-term follow-up, living-donor transplantation may be considered for patients, who recovered from COVID-19, after careful selection with paying attention to precautions.
\end{abstract}

Keywords: Coronavirus; COVID-19; kidney transplant; SARS-CoV-2.

Cite this article as: Kucuk EV, Sit D, Kayabasi H, Tahra A, Sobay R, Gunes Yilmaz SN, et al. The first kidney transplantation after recipient and living donor recovered from COVID-19. North Clin Istanb 2021;8(2):187-189.

CARS-CoV-2 is still a major threat to the world. The virus is highly contagious and life threatening. The first case in Turkey was reported in mid-March 2020 and spread very rapidly. In this pandemic, transplantation activities have largely been affected worldwide. In the United States, the overall reduction in donor transplantation decreased by $51 \%$, whereas kidney transplantation reduction was $90 \%$ in France and $87 \%$ in Spain $[1,2]$.

Herein, we present our experience of kidney transplantation whose recipient and living donor recovered from COVID-19.

\section{CASE REPORT}

A 31-year-old man presented with complaints of abdominal pain, nausea, and vomiting to emergency room 3 months ago. His hemodynamic status was stable except systolic hypertension with $171 \mathrm{mmHg}$. In his first blood analysis, he had moderate anemia with a level of $7.8 \mathrm{~g} / \mathrm{dl}$. He had an acute renal failure (ARF) with a creatinine of $17.59 \mathrm{mg} / \mathrm{dl}$ (baseline at least 2 years ago $1.2 \mathrm{mg} / \mathrm{dl}$ ) and blood urea nitrogen of $235 \mathrm{mg} / \mathrm{dl}$. Ultrasound imaging showed that he had a Grade 2 renal parenchymal disease.

Received: January 22, 2021 Accepted: January 30, 2021 Online: February 17, 2021

Correspondence: Eyup Veli KUCUK, MD. Saglik Bilimleri Universitesi, Umraniye Egitim ve Arastirma Hastanesi, Uroloji Klinigi, Istanbul, Turkey.

Tel: +90 2166321818 - 4618 e-mail: eyupveli@gmail.com

(c) Copyright 2021 by Istanbul Provincial Directorate of Health - Available online at www.northclinist.com 
His nasopharyngeal swab was negative for COVID-19. He had uncontrolled hypertension for 15 years with no adherence to his drugs. He was admitted to our nephrology unit for ARF.

He got hemodialysis (HD) daily and started to take the anti-hypertension drug (perindopril $10 \mathrm{mg}$-amlodipine $10 \mathrm{mg}$ ) to reduce hypertension and sodium bicarbonate to control acidosis. After his evaluation and treatment, he was considered as chronic kidney failure with glomerular filtration rate (GFR) 10 due to hypertension. He was admitted to transplantation list and discharged with structured HD program. His volunteer relatives tested for living-donor transplantation and his uncle ( 50 years old) was found to be $\mathrm{ABO}$ compatible. He was admitted to the hospital and started his immunosuppressant treatment before surgery (tacrolimus and $500 \mathrm{mg}$ pulse corticosteroid). $\mathrm{He}$ and his uncle were tested for COVID-19 before surgery, and they were both positive by a polymerase chain reaction (PCR). There was no finding in thorax computed tomography scan, and he had mild symptoms for COVID-19. He started his treatment (favipiravir, low-molecular-weight heparin, and high-dose Vitamin C) for 5 days. After his tests for COVID-19 negative twice and lack of pulmonary symptoms. His antibody tests ( $\operatorname{IgM}-\operatorname{IgG}$ ) were negative in 15-30 days after COVID. Living donor was also admitted with minor symptoms (no radiological findings) and received COVID treatment (favipiravir, low-molecular-weight heparin, and high-dose Vitamin C) for 5 days. After his tests for COVID-19 negative twice and lack of symptoms, he was discharged. His antibody tests were also negative in 15-30 days.

One month after recovery, the patient and the living donor were admitted for transplantation. They both tested serially $(10,15,20$, and 25 days after discharge) for COVID-19 and they were all negative. We started tacrolimus and anti-thymocyte immunoglobulins (ATG) 2 days before surgery to prevent rejection (high immunologic risk: 5/6 mismatch). Early after transplantation surgery, his creatinine level fell to $1.48 \mathrm{mg} / \mathrm{dl}$ and his estimated GFR was 62. His immunosuppressive regimen was ATG, MMF, tacrolimus, and steroid and prophylactic antiviral and antibiotic treatment also started. One week after surgery, ATG was stopped and discharged on day 15 after surgery. He is now post-operative 45 days, he is stable. The living donor was also followed and discharged 2 days after surgery with a creatinine level of $0.84 \mathrm{mg} / \mathrm{dl}$. Both patients had a negative PCR test for
COVID-19 on day 45 after surgery. Their antibody tests (rapid cassette IgM-IgG) were also negative.

\section{DISCUSSION}

Health systems were strained with COVID-19. To date, nearly 2 million people have died from the virus, and predicament continues. Transplantation activities were delayed. However, after the first wave of the pandemic and break of the strain in health-care systems, normalization for surgeries has started. In this report, we present our experience of living-donor transplantation whose recipient and donor were recovered from COVID-19.

Transplantation is risky when the COVID-19 pandemic is considered. First, surgery has a risk for patients itself. Second, immunosuppressant therapy exposes patients to infection, but patients with chronic kidney disease (CKD) also have a high risk for infection. In a simulation model, Massie et al. [3] found that kidney transplantation had a survival benefit over waitlisted patients. They also found that there was a substantial benefit to the recipient following living-donor kidney transplantation. In a multicenter study from Turkey, Ozturk et al. [4] compared the mortality of the patients with CKD and HD and found no difference between recipients and the control group; however, patients with HD and CKD had higher mortality. Craig-Schapiro et al. 22] compared the clinical results of COVID-19 in patients with waitlisted and recipients, and they showed that waitlisted patients had a higher risk for hospitalization and mortality, and declared that COVID-19 had a dramatic impact and took the patient's opportunity for transplantation.

In Italy, Peluso et al. [5] investigated their bicentric series during the pandemic. Five patients underwent transplant surgery and all surgeries were performed from deceased donors. They delayed living-donor transplantation during this period. Shingare et al. [6] shared their experience with two positive cases after LDKT. Both recipients were positive on day 19 and 7 for COVID-19, and their PCR tests were positive for a long time despite the de-escalation of immunosuppression. They tapered the dose of immunosuppressants, but both patients were positive for a long time.

There are case reports in which it is pointed out that it can be conducted successfully. Ruophael et al. [7] described successful orthotopic liver transplantation with a COVID-19 patient and Dhand et al. [8] reported a suc- 
cessful liver transplantation in a patient who recovered from COVID-19.

\section{Conclusion}

This is the first case report of a recipient and a living donor who recovered from COVID-19 to our knowledge. Although there is missing literature regarding safety concerns and short-term follow-up, living-donor transplantation may be considered for patients who recovered from COVID-19, after careful selection with paying attention to precautions.

Acknowledgements: The authors would like to represent their thankfulness to the Department of Infectious Disease, University of Health Sciences, Umraniye Training and Research Hospital.

Informed Consent: Written informed consent was obtained from the patient for the publication of the case report.

Conflict of Interest: No conflict of interest was declared by the authors.

Financial Disclosure: The authors declared that this study has received no financial support.

Authorship Contributions: Concept - EVK, DS, HK; Design - EVK, AT, RS; Supervision - EVK, HK, DS; Materials - RS, SNGY, EEY, CK; Data collection and/or processing - RS, SNGY, EEY, CK; Analysis and/ or interpretation - EVK, AT, RS; Literature review - AT, RS, SNGY, EEY, CK; Writing - EVK, AT; Critical review - EVK, DS, HK.

\section{REFERENCES}

1. Loupy A, Aubert O, Reese PP, Bastien O, Bayer F, Jacquelinet C. Organ procurement and transplantation during the COVID-19 pandemic. Lancet 2020;395:e95-6. [CrossRef]

2. Craig-Schapiro R, Salinas T, Lubetzky M, Abel BT, Sultan S, Lee JR, et al. COVID-19 outcomes in patients waitlisted for kidney transplantation and kidney transplant recipients. Am J Transplant 2020 Oct [Epub ahead of print], doi: 10.1111/ajt.16351. [CrossRef]

3. Massie AB, Boyarsky BJ, Werbel WA, Bae S, Chow EKH, Avery RK, et al. Identifying scenarios of benefit or harm from kidney transplantation during the COVID-19 pandemic: A stochastic simulation and machine learning study. Am J Transplant 2020;20:2997-3007. [CrossRef]

4. Ozturk S, Turgutalp K, Arici M, Odabas AR, Altiparmak MR, Aydin $Z$, et al. Mortality analysis of COVID-19 infection in chronic kidney disease, haemodialysis and renal transplant patients compared with patients without kidney disease: a nationwide analysis from Turkey. Nephrol Dial Transplant 2020;35:2083-95. [CrossRef]

5. Peluso G, Campanile S, Scotti A, Tammaro V, Jamshidi A, Pelosio L, et al. COVID-19 and Living Donor Kidney Transplantation in Naples during the Pandemic. Biomed Res Int 2020;2020:5703963. [CrossRef]

6. Shingare A, Bahadur MM, Raina S. COVID-19 in recent kidney transplant recipients. Am J Transplant 2020;20:3206-9. [CrossRef]

7. Rouphael C, D’Amico G, Ricci K, Cywinski J, Miranda C, Koval C, et al. Successful orthotopic liver transplantation in a patient with a positive SARS-CoV2 test and acute liver failure secondary to acetaminophen overdose. Am J Transplant 2020 Oct [Epub ahead of print], doi: 10.1111/ajt.16330. [CrossRef]

8. Dhand A, Bodin R, Wolf DC, Schluger A, Nabors C, Nog R, et al. Successful liver transplantation in a patient recovered from COVID-19. Transpl Infect Dis 2020:e13492. [CrossRef] 